\title{
NUTRITIONAL DIAGNOSIS USING AHP WITH THE GARUTI INDEX COMPARED WITH DRIS METHODOLOGY: A CASE STUDY
}

\author{
Víctor Valenzuela \\ Industrial Engineering Student \\ Technical University Federico Santa María \\ Santiago, Chile \\ Email: victor.valenzuela@alumnos.usm.cl
}

\begin{abstract}
The objective of this study is to create a new Analytical Hierarchy Process (AHP) model incorporating the Garuti Index (Garuti 2012) to measure nutrients levels more effectively than the current Diagnosis and Recommendation Integrated System (DRIS) model. To create the model it was necessary to develop the hierarchy of the AHP including macronutrients, micronutrients, and the nutrients in general. The next steps was to measure the weight of all the components and create scales of diagnosis to calculate the Garuti Index and compare the results with the DRIS model. The data set were taken from a DRIS study performed by García S.(2000) on potato leaves from the States of Coahuila and Nuevo Leon in Mexico.
\end{abstract}

Keywords: AHP, Garuti Index, DRIS, Dry Mass production, Nutritional Balance Index.

\section{Introduction}

There are several methods available in the literature to evaluate the nutritional status of agricultural crops. The purpose of this study was to create and evaluate a methodology based on AHP to better diagnosis nutrients status of a plant with more accurate results than the traditional models.

In particular, the Garuti Index (G Index) is incorporated into the study, which measures how close two vectors are to one another. One vector will represent the optimum level of nutrients in a plant and the second vector contains the numbers yielded from the samples of potatoes leaves. The results obtained using this method will were compared with the traditional DRIS process, which is a methodology that uses a set of norms to make a nutritional diagnosis. At the moment, the DRIS model is the standard for measuring the productivity of a plant. Finally, both models will be compared to each other and with the Dry Mass Production (DM).

\section{Literature Review}

For this investigation, it was necessary to begin by researching the AHP Methodology in order to understand the concepts. The book Toma de Decisiones en Escenarios Complejos (Claudio Garuti and Mauricio Escudey, 2005) gave a detailed Review of the AHP Process. The next step required was to understanding the Garuti Index and how to 
apply it to the investigation. The book Measuring in Weighted Environments: Moving From Metric to Order Topology ( Claudio Garuti,2012) explains in detail about the G Index and its uses.

To understand the agricultural aspect it was necessary to do research to understand how to measure the productivity of a plant. Also, it was important to research the traditional methodology to measure nutritional status, which in this case is the DRIS method. Of all the articles researched, the reviews on agriculture that related to this investigation were the thesis "Establecimientos de Normas Dris, Diagnotisco Nutricional y Calibración de las Normas Obtenidas"(García S. 2000) and "DRIS: Concepts and Application on Nutritional Diagnosis in Fruit Crops" (Francisco de Assis Alves, 2004).

Finally, it is important to mention that there are many reviews about the AHP on the agricultural area but this are focused on other themes ( Risk factors evaluations, land use suitability analysis, weighting of agricultural research results). There are no evidence on reviews on nutritional diagnosis using the AHP model, so this study is innovative and It can open a new point of research on this area.

\section{Hypotheses/Objectives}

Our work hypothesis was that the Garuti Index, performs as well or better than the DRIS method in diagnosing plant nutritional status. The objectives of the work are the following:

-To develop a nutritional diagnostic Index, using the Garuti Index and comparing it with the traditional DRIS Methodology.

-To Measure the weight of the nutrients using the AHP process and establish a priority order of importance according to the results.

-To Check the accuracy of the nutritional diagnosis used on the G Index and verify if it yields better results than the DRIS method.

\section{Research Design/Methodology}

The purpose of this investigation is to find a better methodology to diagnose the nutrition of plants based on their components. Currently, one of the traditional models used to diagnose the nutrition of plants is the Diagnosis and Recommendation Integrated System (DRIS), which was developed by Beaufils in 1973. Basically, it is an interpretation of the nutritional balance and the nutrition level of each component using leaf analysis. This method creates dual ratios between nutrients $(\mathrm{N} / \mathrm{P}, \mathrm{N} / \mathrm{K}, \mathrm{K} / \mathrm{Mg}$, etc). The ratios are compared with the DRIS norms that consist of the average and the coefficient of variation of nutrients obtained from high yielding populations. The nutrients are ordered from low to high and the general balance of the plant with all its components can be found using the Nutritional Balance Index (NBI). According to the DRIS, the lower the NBI sample gets (closer to 0 ), the more productive it is. This is inversely related with the DM.

The other methodology used in this investigation is the AHP process, which utilizes the Garuti Index ( $G$ Index) to measure the compatibility between profiles. Garuti created the $\mathrm{G}$ Index and it is an effective method to measure how close two priority vectors are and see their compatibility. According to the G Index, vectors at the level G>0.9 should be compatible. The following steps were performed

Step 1: Create the hierarchy of the model, which for this research includes finding the nutritional diagnosis of potatoes to improve their productivity. The criteria to reach the 
goal were separated into micro- and macronutrients. The micronutrients are $\mathrm{Zn}, \mathrm{B}, \mathrm{Mn}$, $\mathrm{Cu}$, and $\mathrm{Fe}$. The macronutrients are $\mathrm{N}, \mathrm{P}, \mathrm{K}, \mathrm{Ca}$, and $\mathrm{Mg}$.

Step 2: Measure the weight or the level of importance for macronutrients and micronutrients criteria under expert's criterion. In this case, Ortega measured the macronutrients and the inconsistency rate was $8.52 \%$. For micronutrients, the inconsistency rate was $4.04 \%$, so both evaluations were acceptable. Evaluation of weight on the components may vary depending on the region in which the analysis is performed. Step 3: Create a scale of diagnosis for the nutrients criteria, which in this case is classified as optimal, very good, good, regular, below regular, and poorest.

Step 4: Measure the G Index, using all the information obtained above.

\section{Data/Model Analysis}

According to this model, the hierarchy for decision-making in nutritional diagnosis of plants is described in this figure:

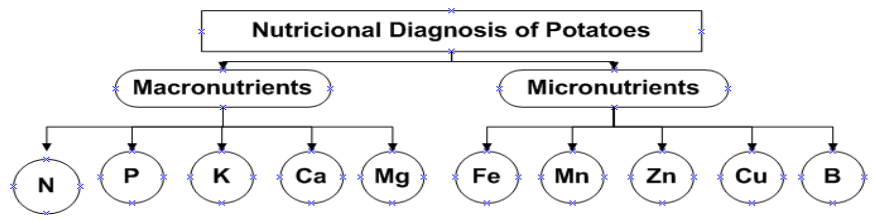

Figure :Hierarchy of the model

To measure the weights, it was necessary to obtain the opinion of an agricultural expert(Ortega, 2013). For the measured alternatives, there were no difference in weight between macronutrients and micronutrients so they are both of equal importance. The judgment matrices of the nutrients and the ICA are present on the table below:

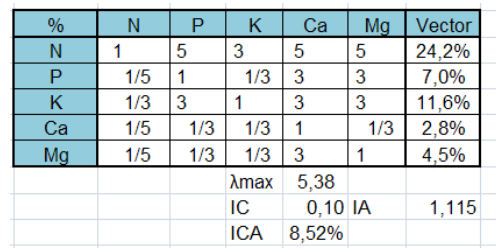

\begin{tabular}{|c|c|c|c|c|c|c|}
\hline PPM & $\mathrm{Fe}$ & $\mathrm{Mn}$ & $\mathrm{Zn}$ & $\mathrm{Cu}$ & $\mathrm{B}$ & Vector \\
\hline $\mathrm{Fe}$ & 1 & 1 & 1 & 9 & 5 & $16,6 \%$ \\
\hline $\mathrm{Mn}$ & 1 & 1 & 1 & 5 & 3 & $13,1 \%$ \\
\hline $\mathrm{Zn}$ & 1 & 1 & 1 & 5 & 3 & $13,1 \%$ \\
\hline $\mathrm{Cu}$ & $1 / 9$ & $1 / 5$ & $1 / 5$ & 1 & $1 / 5$ & $1,9 \%$ \\
\hline $\mathrm{B}$ & $1 / 5$ & $1 / 3$ & $1 / 3$ & 5 & 1 & $5,2 \%$ \\
\hline \multicolumn{6}{|c|}{$\lambda \max 5,18$} \\
\hline & IC & 0,04 & IA & 1,115 \\
\hline
\end{tabular}

Table 1 \& 2: Weight of macronutrients and micronutrients.

To get better results in the model, it was necessary to create a scale of measurement in order to assign the nutrients to a specific category according to the ranges. This scale was built using the Dry Matter(potato yield) production.

Once all of this information was compiled, it was possible to make a profile of the potato leaf samples and it can be compared with the optimal profile using the $G$ index. According to our results, out of the 142 profile samples used in this investigation, 87 samples were over $90 \%$ on G Index, which means they are compatible with the optimal profile $(61.3 \%)$. To understand if these results are reflecting the reality, it is necessary compare the G Index results with the DM production of that sample. The results are shown in the following graph: 


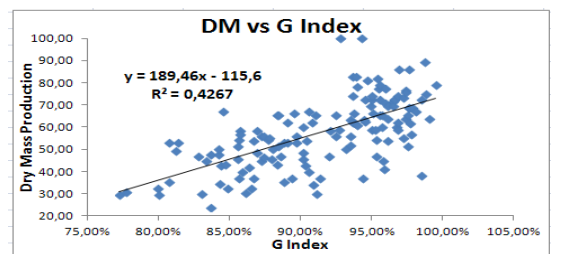

Graph 1: Relationship between the $G$ index and the DM

According to the graph, the results are the expected and are compatible with reality. If the $\mathrm{G}$ index is high, it yields better production and if the $\mathrm{G}$ index is low, the sample is not perfectly healthy and therefore it would have a low production level. Finally, it is necessary to make a comparison with the DRIS method to analyze the similarities between both methods.
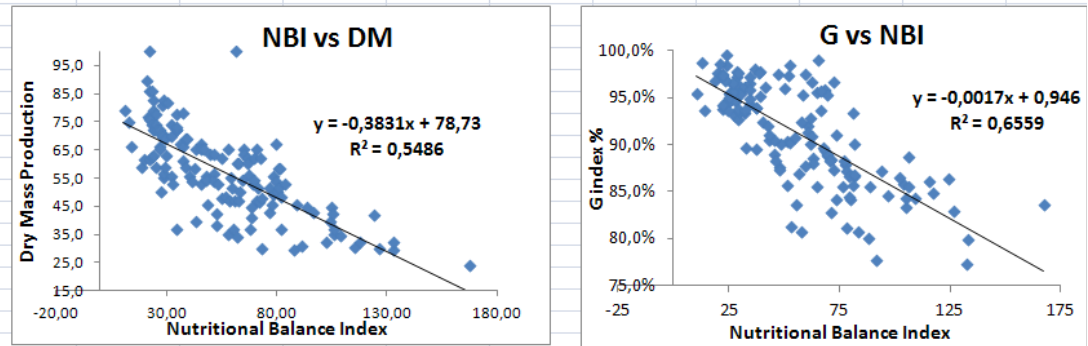

Graph 2: Relationship between NBI and DM Graph 3: Relationship between the G index and NBI

The Potato DM increased with the increase in Nutrient Balance Index, so if the potato has poor productivity it would have a high NBI. The comparison of the G Index and the NBI shows that there is a clear inverse proportion; so if the $\mathrm{G}$ index is high (very compatible with the optimal profile) the NBI should be lower as can be seen in the graph.

Finally, it is necessary to apply sensitivity analysis to the nutrients to determining how it influences the G index. According to the expert, it is only necessary to use it on the 3 most important nutrients to the agriculture area which are $\mathrm{N}, \mathrm{P}$ and $\mathrm{K}$. Using a Variation on $\pm 10 \%$ on the weights the results are:

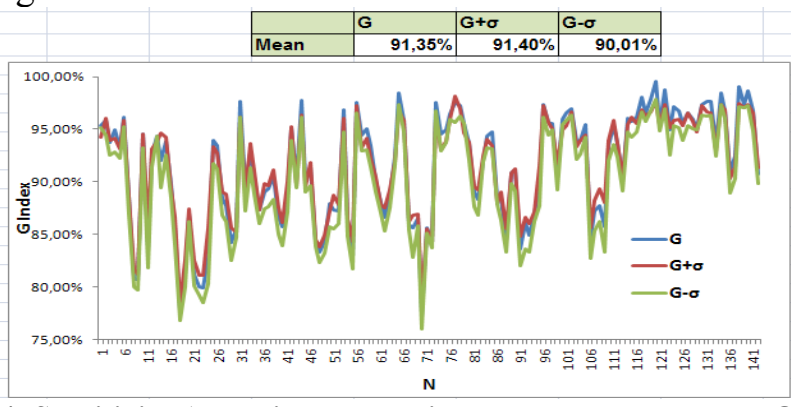

Graph 4: Sensitivity Analysis on the weight on N, P and $K$ on the G Index.

When the weights on $\mathrm{N}, \mathrm{P}$ and $\mathrm{K}$ are increased on $10 \%$, there is not an important variation on the $\mathrm{G}$ index Mean( $0,05 \%$ variation). When the weights are decreased, it changes more on the mean of the $\mathrm{G}$ index(1,34\% variation) and the results are reflected on the graph 4. So the G Index is more sensitive when these weights are decreased, but still the results are compatible $(\mathrm{G}>90 \%)$ so it means that for significant variations on the weight, does not greatly affect the fact to be compatible with a solid pattern and gives assurance that is a good sign. 


\section{Limitations}

For this research there is one unsatisfactory aspect in the results. The measurement scale is not perfectly calibrated and it is reflected in the results of the $G$ index. The results show high compatibility even if the production is not very high, so it needs to be modified in the future in order to improve the model (a fine tuning feedback process). Other than that, the results are very satisfactory.

\section{Conclusions}

It was demonstrated that $\mathrm{G}$ Index can be applied to make a nutritional diagnostic of potatoes and could expand to other areas related to agriculture if the same model is used for other plants. If the G Index is further improved, it could completely replace the DRIS method for 3 reasons:

1. It can measure the nutrients importance and this could be customized according to the geographic area.

2. It can measure the exact percentage of how low or high the nutrient level is, so it can be used to know how necessary it is to fertilize the specific field.

3. If the measurement scale is appropriately corrected the $\mathrm{G}$ index shows how compatible the sample is with the optimal profile and can conclude whether the plant is healthily productive or not. Also, it may say which is the specific nutrient that is needed and how much it need, measuring the proximity (compatibility) between the two profiles (sample and ideal).

The contribution of this investigation using the AHP and G index in this area could be the first of future research. This model can still be improved with more variables. For example, the model can be modified to add more information if $\mathrm{m}$ for example another kind of plant that produces proteins or carbohydrates is used.

This research would not be possible without the collaborative efforts of the following: Rodrigo Ortega and Roberto Muñoz, professors at Technical University Federico Santa Maria and Claudio Garuti expert on the AHP methodology.

\section{Key References}

Garcia, S. (2000). Establecimientos de normas dris, diagnotisco nutricional y calibración de las normas obtenidas para el cultivo de las papas (thesis). Retrieved from http://cdigital.dgb.uanl.mx/te/1020150639/1020150639.PDF

Garuti, C., \& Escudey, M. (2005). Toma de decisiones en escenarios complejos. Santiago: Universidad de Santiago de Chile.

Garuti, C. (2012). Measuring in weighted environments: moving from metric to order topology. Santiago: Universidad Tecnica Federico Santa Maria.

Ortega, R.(2013) Expert criteria(personal communication).

De Assis Alves, F.(2004). DRIS: Concepts and Application on Nutritional Diagnosis in Fruit Crops. Piracicaba, SP- Brazil. 